\title{
Smoking and Heberden Nodes: Analysis of Data from the Osteoarthritis Initiative
}

\author{
R. Constance Wiener ${ }^{1,2}$ and Alcinda K. Trickett Shockey ${ }^{3}$ \\ ${ }^{1}$ Department of Dental Practice and Rural Health, School of Dentistry, West Virginia University, Morgantown, WV 26506, USA \\ ${ }^{2}$ Department of Epidemiology, School of Public Health, West Virginia University, Morgantown, WV 26506, USA \\ ${ }^{3}$ Department of Periodontics, Division of Dental Hygiene, West Virginia University, Morgantown, WV 26506, USA
}

Correspondence should be addressed to R. Constance Wiener; rwiener2@hsc.wvu.edu

Received 19 November 2015; Accepted 10 April 2016

Academic Editor: Jeanine M. Buchanich

Copyright (c) 2016 R. C. Wiener and A. K. T. Shockey. This is an open access article distributed under the Creative Commons Attribution License, which permits unrestricted use, distribution, and reproduction in any medium, provided the original work is properly cited.

\begin{abstract}
Purpose. Dental hygienists, dentists, and other workforce providers who depend upon their hands for employment are acutely aware of the need to protect their hands to ensure a successful career. Recent research has suggested that smoking may be protective of hand osteoarthritis. The purpose of this study is to determine the association between smoking and Heberden's nodes. Methods. Data from the Osteoarthritis Initiative were used in a cross-sectional, secondary data analysis of self-reported current smoking/never smoking and the presence/absence of Heberden's nodes, the hard enlargements of the joints nearest the fingertips (distal interphalangeal joints). Analyses included descriptive statistics, Chi-square associations with Heberden's nodes, and logistic regressions. Results. In adjusted analysis, smoking had an adjusted odds ratio for Heberden's nodes of 0.832 [95\% confidence interval: 0.60, 1.14] which failed to reach significance $(P=.2488)$. In the selected model, females were more likely than males to have Heberden's nodes; non-Hispanic Blacks were less likely than non-Hispanic Whites to have Heberden's nodes; and older age groups were more likely than the youngest age group to have Heberden's nodes. Conclusion. Smoking did not provide protection against Heberden's nodes in this study of US participants in the Osteoarthritis Initiative.
\end{abstract}

\section{Introduction}

Osteoarthritis is the most common form of arthritis involving entire joints (cartilage, joint lining, ligaments, and underlying bone) [1] and mainly affecting the axial skeleton and large appendicular joints [2]. Over 21\% of US adults (an estimated 46.4 million) have osteoarthritis [3]. When considering lifetime risk of symptomatic osteoarthritis, researchers reported nearly $50 \%$ of adults will develop osteoarthritis by age of 85 years [4]. Many of the epidemiological researchers for osteoarthritis have considered various predictors and associated morbidities involved with osteoarthritis. It has been associated with body mass index [5], low Vitamin D [6, 7], and increased consumption of soft drinks in men [8] and in women with limited milk consumption [9], not breastfeeding [10], and giving birth [10]. Inconclusive and contradictory associations have been reported concerning associations of osteoarthritis and sex in which some researchers found positive associations $[7,11,12]$ while others did not [13] and with smoking in which some researchers found positive associations [14], others found protective associations [15, 16], and others did not find any association [13].

Hand osteoarthritis is highly prevalent, impacts function, and leads to considerable pain, stiffness, and disability $[17,18]$. There are $26.2 \%$ of women and $13.4 \%$ of men aged 71 years and above who have hand osteoarthritis [19]. In an age-sex standardized analysis, researchers reported an incidence of hand osteoarthritis of 100/100,000 person-years (as compared with $88 / 100,000$ person-years for the hip) [20]. Nevertheless, epidemiological studies of hand osteoarthritis are limited $[18,19]$. Hands often develop hard tissue enlargements. If the enlargements involve the joints nearest the fingertips, which are the distal interphalangeal joints, the enlargements are termed Heberden's nodes. If the enlargements involve the 2nd joints from the fingertips, which are the proximal interphalangeal joints, the enlargements are termed Bouchard's nodes. 
Hand osteoarthritis has been defined as the presence of (1) hand pain/aching/stiffness; (2) at least 2 bony nodes on the $2 \mathrm{nd} / 3 \mathrm{rd}$ distal/proximal interphalangeal/first trapeziometacarpal (base of thumb) joints; (3) less than 3 swollen metacarpophalangeal joints; and (4) at least 2 Heberden's nodes, or deformity of at least 2 of the $2 \mathrm{nd} / 3 \mathrm{rd}$ distal/proximal interphalangeal/first trapeziometacarpal joints [21]. The disease process for hand osteoarthritis is poorly understood, and it is yet to be determined if metabolic factors are involved [18]. Some researchers have indicated that the hard tissue enlargements on the distal interphalangeal joints, Heberden's nodes, may be genetic markers for general arthritis [22]. If this is the case, an environmental factor, such as smoking, may have an epigenetic role [23].

Smoking is a potentially modifiable risk factor for many conditions and diseases including lung cancer and other cancers, coronary heart disease and other heart diseases, cerebrovascular disease and other vascular diseases, diabetes mellitus, respiratory diseases (including chronic obstructive pulmonary disease), rheumatoid arthritis, sudden unexplained infant death, inflammation, adverse effects on the immune system, and bone health [24]. Smoking causes more than 480,000 deaths annually in the US [24]. In a report of the U.S. Department of Health and Human Services (2014) [24], the authors indicated that smoking harms nearly every organ in the body. There is a biological plausibility that smoking is associated with hand osteoarthritis and one feature in particular-Heberden's nodes. Previous researchers have reported conflicting results as to the association of smoking and osteoarthritis in general and smoking with Heberden's nodes [2]. The purpose of this study is to determine the association of smoking and Heberden's nodes.

\section{Materials and Methods}

2.1. Data Source. The data used in the preparation of this paper were obtained from the Osteoarthritis Initiative (OAI) database, which is available for public access at http://www.oai.ucsf.edu/. Specific datasets used were from the version 0.2.2 (2009) physical exam/measurements file: subject characteristics file; risk factors file; joint symptoms/function file; biomarkers file; and medical history file. The version V21 (2015) enrollee file was also used.

The researchers for the OAI conducted a longitudinal study at four clinical centers (Brown University School of Medicine/Memorial Hospital of Rhode Island in Pawtucket; The Ohio State University in Columbus; University of Pittsburgh in Pittsburgh; and University of Maryland/John Hopkins University in Baltimore) and one data collection center (University of California, San Francisco School of Medicine) in a design to develop public domain osteoarthritis research through the development and maintenance of an osteoarthritis natural history database containing biochemical, genetic, and imaging biomarkers for osteoarthritis [25]. Participant exclusion criteria included refusal to sign informed consent documents, self-reported prevalent rheumatoid arthritis, bilateral total knee replacement or expected bilateral knee replacement within 3 years, severe joint space narrowing in both knees determined at baseline, pregnancy, the use of more than a single cane to aid in walking for more than $50 \%$ of the time, conditions which might cause an inability to participate in the entire length of the study, potential move from the clinic area within 3 years, enrollment as a participant in a double-blind randomized controlled study, inability to have a 3.0 Tesla MRI, or inability to provide a blood sample [25]. There were 4769 participants, aged $45-79$ years, in the source data from which our sample was drawn. Additional documentation describing various aspects of the design and methods of the OAI is available at the OAI online website (http://www.oai.ucsf.edu/).

2.2. Participant Eligibility. Participants for this study were included if they (1) were current or never smokers; (2) provided a response to the question about any obvious hard bumps on the joints nearest to the fingertips; and (3) had complete data on the other variables of interest in the study (age, sex, race/ethnicity, alcohol use, educational level, comorbidities, height, weight, family history, physical summary score, and knee osteoarthritis). Participants were excluded if they were former smokers or if they did not provide a response concerning any obvious hard bumps on the joints nearest to the fingertips or had incomplete data on the other variables of interest in the study. From the 4769 participants in the OAI, there were 2723 participants who had data on all of the variables of interest and were therefore eligible for this study.

2.3. Key Dependent Variable. The presence or absence (yes, no) of Heberden's nodes was the key dependent variable. It was determined by the self-report of the participant of any obvious hard bumps on the joints nearest to the fingertips. This was a question asked during the initial eligibility interview.

2.4. Key Independent Variable. The key independent variable is smoking (current, never). Never smoking was determined by the self-report of the participant that he or she had never smoked 100 cigarettes (5 packs) in his or her life. A followup question of current smoking status identified current smokers. Former smokers were excluded from the study.

2.5. Other Variables. Also included in the analyses were sex (male, female); age (45 to less than 56 years, 56 to less than 66 years, and 66 years and above); race/ethnicity (nonHispanic White, non-Hispanic Black, and Hispanic/other); education (high school graduate or less, more than high school graduate); body mass index (less than 25, 25 to less than 30 , and 30 and above); Charlson index $(0,1$, and above); and mother/father/sister/brother having had knee replacement (yes, no). The presence of knee osteoarthritis was determined by the right-side baseline radiographs scored on the composite quasi-Kellgren and Lawrence graded as (0) normal, (1) possible, (2) mild, (3) moderate, and (4) severe OA. Physical summary scores (categorized as quartiles) from the Medical Outcomes Study Short Form-12 version 2 physical summary scale were also included. 
2.6. Statistical Analyses. The analyses for the study were conducted using SAS 9.2 ${ }^{\circledR}$ software (SAS Institute, Chicago, IL). The data were analyzed for a description of the sample characteristics, bivariate analyses of the variables by Heberden's nodes, and logistic regression on Heberden's nodes. Unadjusted and adjusted logistic regressions were completed using the eligible participants as the domain in the analyses.

\section{Results and Discussion}

The sample consisted of 2723 participants. There were $59.7 \%$ (1625) females, 78.9\% (2148) non-Hispanic Whites, $19.0 \%$ (516) non-Hispanic Blacks, and 2.2\% (59) Hispanic/other. In terms of age groups, there were $38.5 \%$ (1047) participants aged 45 to less than 56 years; $30.4 \%$ (827) aged 56 to less than 66 years; and $31.2 \%$ aged 66 years and above. There were $26.0 \%$ with a body mass index below 25 (normal weight); $38.7 \%$ with a body mass index between 25 and less than 30 (overweight); and $35.3 \%$ with a body mass index of 30 or above (obese). Most participants $(76.2 \%)$ had a Charlson index of 0 and an education above high school (84.1\%) and did not have a mother/father/sister/brother who had a knee replacement. There were $18.8 \%$ of participants who had a normal right knee radiographic evaluation and $5.5 \%$ of participants who had a severe right knee radiographic evaluation. There were $30.1 \%$ (819) of participants who reported having Heberden's nodes and 11.4\% (310) of participants who reported current smoking. The Medical Outcomes Study Short Form-12 version 2 physical summary scale quartile cutpoints were $43.06,51.24$, and 56.14 for $25 \%, 50 \%$, and $75 \%$, respectively. Details of the analyses are presented in Table 1.

Table 2 includes the results of the Chi-square analyses between Heberden's nodes and the variables. Smoking, the key independent variable of interest, was significantly related to Heberden's nodes $(P=.0006)$. Other significant relationships with Heberden's nodes were with sex, race/ethnicity, age, body mass index, right knee radiographic evaluation, mother/father/sister/brother who had a knee replacement, education, and the Medical Outcomes Study Short Form-12 version 2 physical summary scale quartiles. Charlson index and alcohol usage failed to reach significance in association with Heberden's nodes.

Table 3 includes the results of the logistic regressions of smoking on Heberden's nodes. In unadjusted analysis, current smokers were less likely to have Heberden's nodes than never smokers (less than 5 packs/lifetime). The odds ratio for current smokers, as compared with never smokers, was 0.61 (95\% confidence interval: $0.46,0.81 ; P=.0007)$. When the other significant variables were included in the model, smoking was attenuated to an adjusted odds ratio of 0.83 [95\% confidence interval: $0.60,1.14$ ] which failed to reach significance $(P=.2488)$. In the selected model, females were more likely than males to have Heberden's nodes; nonHispanic Blacks were less likely than non-Hispanic Whites to have Heberden's nodes; older age groups were more likely than the youngest age group to have Heberden's nodes; people in the lower quartiles on the Medical Outcomes Study Short Form-12 version 2 physical summary scale were more likely to have Heberden's nodes than people in the highest quartile;
TABLE 1: Sample description, Osteoarthritis Initiative data.

\begin{tabular}{|c|c|c|}
\hline & Number & Percent \\
\hline All & 2723 & 100 \\
\hline \multicolumn{3}{|l|}{ Heberden's nodes } \\
\hline Yes & 819 & 30.1 \\
\hline No & 1904 & 69.9 \\
\hline \multicolumn{3}{|l|}{ Smoking } \\
\hline Yes, current & 310 & 11.4 \\
\hline Never (<5 packs/lifetime) & 2413 & 88.6 \\
\hline \multicolumn{3}{|l|}{ Sex } \\
\hline Female & 1625 & 59.7 \\
\hline Male & 1098 & 40.3 \\
\hline \multicolumn{3}{|l|}{ Race/ethnicity } \\
\hline Non-Hispanic White & 2148 & 78.9 \\
\hline Non-Hispanic Black & 516 & 18.9 \\
\hline Hispanic/other & 59 & 2.2 \\
\hline \multicolumn{3}{|l|}{ Age in years } \\
\hline 45 to $<56$ & 1047 & 38.5 \\
\hline$\geq 56$ to $<66$ & 827 & 30.4 \\
\hline$\geq 66$ & 849 & 31.2 \\
\hline \multicolumn{3}{|l|}{ Body mass index } \\
\hline$<25$ (normal weight) & 709 & 26.0 \\
\hline$\geq 25$ to $<30$ (overweight) & 1054 & 38.7 \\
\hline$\geq 30$ (obese) & 960 & 35.3 \\
\hline \multicolumn{3}{|c|}{ Right knee radiographic evaluation } \\
\hline Normal & 512 & 18.8 \\
\hline Possible osteoarthritis & 957 & 35.1 \\
\hline Mild & 544 & 20.0 \\
\hline Moderate & 559 & 20.5 \\
\hline Severe & 151 & 5.5 \\
\hline \multicolumn{3}{|l|}{ Family history of osteoarthritis } \\
\hline Yes & 248 & 9.1 \\
\hline No & 2475 & 90.9 \\
\hline \multicolumn{3}{|l|}{ Charlson index } \\
\hline 0 & 2074 & 76.2 \\
\hline$\geq 1$ & 649 & 23.8 \\
\hline \multicolumn{3}{|l|}{ Education } \\
\hline High school or less & 434 & 15.9 \\
\hline More than high school & 2289 & 84.1 \\
\hline \multicolumn{3}{|l|}{ Alcohol use (drinks/week) } \\
\hline $0-3$ & 2084 & 76.5 \\
\hline $4-7$ & 355 & 13.0 \\
\hline $8-14$ & 198 & 7.3 \\
\hline 15 and above & 86 & 3.2 \\
\hline \multicolumn{3}{|c|}{${ }^{1}$ Medical Outcomes Study Short Form-12 } \\
\hline Quartile 1 & 655 & 24.1 \\
\hline Quartile 2 & 668 & 24.5 \\
\hline Quartile 3 & 643 & 23.6 \\
\hline Quartile 4 & 757 & 27.8 \\
\hline
\end{tabular}

${ }^{1}$ Medical Outcomes Study Short Form-12 version 2 physical summary scale quartile cut-points: $25 \%=43.06 ; 50 \%=51.24$; and $75 \%=56.14$.

and people with a BMI of 30 and above were less likely to have Heberden's nodes than people with a BMI of less than 25. 
TABLE 2: Chi-square analysis of Heberden's nodes by the variables, Osteoarthritis Initiative data.

\begin{tabular}{|c|c|c|c|c|c|}
\hline Heberden's nodes & Yes & $\begin{array}{c}\text { Row } \\
\%\end{array}$ & No. & $\begin{array}{c}\text { Row } \\
\%\end{array}$ & $P$ value \\
\hline Smoking & & & & & .0006 \\
\hline Yes, current & 67 & 21.6 & 243 & 78.4 & \\
\hline Never ( $<5$ packs/lifetime) & 752 & 31.2 & 1661 & 68.8 & \\
\hline Sex & & & & & $<.0001$ \\
\hline Female & 647 & 39.8 & 978 & 60.2 & \\
\hline Male & 172 & 15.7 & 926 & 84.3 & \\
\hline Race/ethnicity & & & & & $<.0001$ \\
\hline Non-Hispanic White & 706 & 32.9 & 1442 & 67.1 & \\
\hline Non-Hispanic Black & 90 & 17.4 & 426 & 82.6 & \\
\hline Hispanic/other & 23 & 39.0 & 36 & 61.0 & \\
\hline Age & & & & & $<.0001$ \\
\hline 45 to $<56$ & 187 & 17.9 & 860 & 82.1 & \\
\hline$\geq 56$ to $<66$ & 269 & 32.5 & 558 & 67.5 & \\
\hline$\geq 66$ & 363 & 42.8 & 486 & 57.2 & \\
\hline Body mass index & & & & & $<.0001$ \\
\hline$<25$ (normal weight) & 247 & 34.8 & 462 & 65.2 & \\
\hline$\geq 25$ to $<30$ (overweight) & 330 & 31.3 & 724 & 68.7 & \\
\hline$\geq 30$ (obese) & 242 & 25.2 & 718 & 74.8 & \\
\hline $\begin{array}{l}\text { Right knee radiographic } \\
\text { evaluation }\end{array}$ & & & & & .0190 \\
\hline Normal & 124 & 24.2 & 388 & 75.8 & \\
\hline Possible osteoarthritis & 288 & 30.1 & 669 & 69.9 & \\
\hline Mild & 178 & 32.7 & 366 & 67.3 & \\
\hline Moderate & 181 & 32.4 & 378 & 67.6 & \\
\hline Severe & 48 & 31.8 & 103 & 68.2 & \\
\hline $\begin{array}{l}\text { Family history of } \\
\text { osteoarthritis }\end{array}$ & & & & & .0172 \\
\hline Yes & 91 & 36.7 & 157 & 63.5 & \\
\hline No & 728 & 29.4 & 1747 & 70.6 & \\
\hline Charlson index & & & & & .7836 \\
\hline 0 & 621 & 29.9 & 1453 & 70.1 & \\
\hline$\geq 1$ & 198 & 30.5 & 451 & 69.5 & \\
\hline Education & & & & & .0017 \\
\hline High school or less & 158 & 36.4 & 276 & 63.6 & \\
\hline More than high school & 661 & 28.9 & 1628 & 71.1 & \\
\hline Alcohol use (drinks/week) & & & & & .1025 \\
\hline $0-3$ & 646 & 31.0 & 1438 & 69.0 & \\
\hline $4-7$ & 104 & 29.3 & 251 & 70.7 & \\
\hline $8-14$ & 45 & 22.7 & 153 & 77.3 & \\
\hline 15 and above & 24 & 27.9 & 62 & 72.1 & \\
\hline${ }^{1}$ MOS SF-12 quartiles & & & & & .0037 \\
\hline Quartile 1 & 218 & 33.3 & 437 & 66.7 & \\
\hline Quartile 2 & 217 & 32.5 & 451 & 67.5 & \\
\hline Quartile 3 & 193 & 30.0 & 450 & 70.0 & \\
\hline Quartile 4 & 191 & 25.2 & 566 & 74.8 & \\
\hline
\end{tabular}

${ }^{1}$ Medical Outcomes Study Short Form-12 version 2 physical summary scale.

The purpose of this study was to explore the association of smoking and Heberden's nodes. The results were that the adjusted odds ratio for smoking on Heberden's nodes failed to reach significance $(P=.2337)$. Interaction analysis with family history did not change the results. However, female smokers and female nonsmokers were more likely to have
TABLE 3: Odds ratios and 95\% confidence intervals from logistic regression on Heberden's nodes, Osteoarthritis Initiative data.

\begin{tabular}{|c|c|c|}
\hline & $\begin{array}{c}\text { Odds ratio } \\
\text { [confidence } \\
\text { interval] }\end{array}$ & $P$ value \\
\hline \multicolumn{3}{|l|}{ Unadjusted } \\
\hline \multicolumn{3}{|l|}{ Smoking } \\
\hline Yes, current & $0.61[0.46,0.81]$ & .0007 \\
\hline Never ( $<5$ packs/lifetime $)$ & Referent & \\
\hline \multicolumn{3}{|l|}{ Adjusted model } \\
\hline Smoking & & .2488 \\
\hline Yes, current & $0.83[0.60,1.14]$ & \\
\hline Never $(<5$ packs/lifetime $)$ & Referent & \\
\hline Sex & & $<.0001$ \\
\hline Female & $3.65[2.98,4.48]$ & \\
\hline Male & Referent & \\
\hline \multicolumn{3}{|l|}{ Race/ethnicity } \\
\hline Non-Hispanic White & Referent & \\
\hline Non-Hispanic Black & $0.38[0.29,0.49]$ & $<.0001$ \\
\hline Hispanic/other & $1.12[0.61,2.08]$ & .7094 \\
\hline \multicolumn{3}{|l|}{ Age } \\
\hline 45 to $<56$ & Referent & \\
\hline$\geq 56$ to $<66$ & $1.97[1.57,2.48]$ & $<.0001$ \\
\hline$\geq 66$ & $2.81[2.22,3.55]$ & $<.0001$ \\
\hline \multicolumn{3}{|l|}{ Body mass index } \\
\hline$<25$ (normal weight) & Referent & \\
\hline$\geq 25$ to $<30$ (overweight) & $1.02[0.81,1.27]$ & .8988 \\
\hline$\geq 30$ (obese) & $0.72[0.57,0.93]$ & .0105 \\
\hline \multicolumn{3}{|c|}{ Right knee radiographic evaluation } \\
\hline Normal & Referent & \\
\hline Possible osteoarthritis & $1.16[0.89,1.52]$ & .2722 \\
\hline Mild & $1.22[0.90,1.65]$ & .1984 \\
\hline Moderate & $1.16[0.86,1.58]$ & .3359 \\
\hline Severe & $1.17[0.74,1.84]$ & .4998 \\
\hline \multicolumn{3}{|l|}{ Family history of osteoarthritis } \\
\hline Yes & $1.24[0.92,1.69]$ & .1625 \\
\hline No & Referent & \\
\hline \multicolumn{3}{|l|}{ Education } \\
\hline High school or less & $1.16[0.91,1.50]$ & .2372 \\
\hline More than high school & Referent & \\
\hline \multicolumn{3}{|l|}{ MOS SF-12 quartiles ${ }^{1}$} \\
\hline Quartile 1 & $1.53[1.18,1.98]$ & .0015 \\
\hline Quartile 2 & $1.40[1.09,1.80]$ & .0096 \\
\hline Quartile 3 & $1.28[0.99,1.64]$ & .0577 \\
\hline Quartile 4 & Referent & \\
\hline
\end{tabular}

Heberden's nodes than male nonsmokers ( $\mathrm{AOR}=2.95$ and 3.69, resp.; $P<.0001$ ); and smokers aged 45-56 years, smokers aged 56 years and above, and nonsmokers aged 
56 years and above were more likely to have Heberden's nodes than young nonsmokers $(\mathrm{AOR}=1.24,1.94,3.00$, resp.).

The literature has few studies involving the relationship between hand osteoarthritis and smoking, [26]. There are even fewer studies between Heberden's nodes and smoking with which we could compare our results. This study's results are similar to results of Haara et al. [26] who studied Kellgren and Lawrence Grade $2+$ osteoarthritis in any finger and smokers who smoked 20 or more cigarettes per day. The results in that study included an adjusted odds ratio of 0.72 [95\% confidence interval: 0.48, 1.09] [26]. In a study of 443 Chuvashian (Russian) men, no association of smoking and hand osteoarthritis was determined (Chi-square $P=.49$ ) [27].

This study's results are also similar to the risk ratio for current smoking on hand osteoarthritis in which the adjusted odds ratio was 0.99 [95\% confidence interval: $0.75,1.31$ ] [28]. The definition for smoking exposure (i.e., current smoking and never smoking) used by Wilder et al. [28] was the same as the definition used for this study. However, protective results of smoking with Heberden's nodes in women [29] and protective results of smoking and osteoarthritis in knees and large joints are also reported in the literature [15, 16, 30]. It has been suggested that there is a differential effect of nicotine on human chondrocyte glycosaminoglycan and collagen synthesis [31].

3.1. Plausible Biological Mechanism. It has been reported that the relationship of smoking with Heberden's nodes and osteoarthritis is variable [2] and that the etiology of osteoarthritis may be different at different body sites [16]. Additionally, the effects of nicotine may also be different at different body sites [16]. Although nicotine was shown to be beneficial to chondrocyte metabolism, it was also shown to destroy chondrocytes at the intervertebral disk, but not at the knee [31-33].

\section{Conclusion}

Workforce losses due to hand osteoarthritis would place a great burden on society. This is particularly true for healthcare access to care issues in which certain professions require repetitive motions (such as with dental hygiene). The public health impact is a concern, especially for high risk, special needs populations. Hand osteoarthritis and its implications may become a factor in recruitment to various professions and workforce numbers. Determining and understanding factors associated with hand osteoarthritis and factors not implicated with hand osteoarthritis are important for individuals and for workforce preparation.

We failed to reject the null hypothesis of no difference in the number of Heberden nodes among individuals who smoke and individuals who do not smoke; we did not provide any clear evidence of a protective effect of smoking. These findings are similar to the findings of many studies of smoking and hand osteoarthritis but are not similar to previous findings concerning Heberden's nodes in which smoking was protective. The implications of this study are that smoking has not shown any beneficial effects in protecting the hands. With current knowledge of the harms of smoking, this study adds to the mounting knowledge in the literature that there are few benefits and many known harms of smoking.

\section{Additional Points}

The researchers of the OAI intended to provide a wide longitudinal database for public use; it was not intended to be nationally representative. As a result, the number of smokers in the study is not representative of the nation $(11.4 \%$ in the sample as compared with $17.8 \%$ nationally) [34]. This was a limitation of the available data. There are limited studies available to determine if the smoking exposure in studying osteoarthritis should be current smoking, as is needed for studies of myocardial infarctions, or if it should be packyears/total duration, as is needed for studies of lung cancer [28]; therefore this limitation also applies to this study.

\section{Ethical Approval}

This cross-sectional study, a secondary data analysis (nonhuman subject research) of the OAI data, was acknowledged by the West Virginia University Institutional Review Board (Protocol no. 1509861595) and did not include experimentation involving human subjects or animals. The West Virginia University Institutional Review Board does not approve nor disapprove research which involves nonhuman subjects, such as this project; however the members of the Board review the protocol, acknowledge the review, and keep the protocol on file. The research was conducted in full accordance with the World Medical Association Declaration of Helsinki.

As with any study which relies upon self-report, there is the possibility of misclassification due to inaccurate report of smoking, Heberden's nodes, or the other self-reported variables. Self-reported data remains a weakness of all crosssectional studies. However, overall, the large sample made it possible to include many additional variables in the model in the explanation of the relationship of smoking and Heberden's nodes. Additionally, the data were quality data intended for secondary data analysis.

\section{Disclosure}

The content is solely the responsibility of the authors and does not necessarily represent the official views of the National Institutes of Health. The funders had no role in study design, data collection and analysis, decision to publish, or preparation of the paper. The OAI is a public-private partnership comprised of five contracts (N01-AR-2-2258; N01-AR-2-2259; N01-AR-2-2260; N01-AR-2-2261; and N01AR-2-2262) funded by the National Institutes of Health, a branch of the Department of Health and Human Services, and conducted by the OAI Study Investigators. Private funding partners include Merck Research Laboratories; Novartis Pharmaceuticals Corporation, GlaxoSmithKline; and Pfizer, Inc. Private sector funding for the OAI is managed by the Foundation for the National Institutes of Health. This paper 
was prepared using an OAI public use dataset and does not necessarily reflect the opinions or views of the OAI investigators, the NIH, or the private funding partners.

\section{Competing Interests}

The authors declare that they have no competing interests.

\section{Acknowledgments}

Research reported in this paper was supported by the National Institute of General Medical Sciences of the National Institutes of Health under Award no. U54GM104942.

\section{References}

[1] CDC. Osteoarthritis, Centers for Disease Control and Prevention, 2014, http://www.cdc.gov/arthritis/basics/osteoarthritis .htm.

[2] E. L. Radin, "Who gets osteoarthritis and why?" The Journal of Rheumatology Supplement, vol. 70, pp. 10-15, 2004.

[3] C. G. Helmick, D. T. Felson, R. C. Lawrence et al., "Estimates of the prevalence of arthritis and other rheumatic conditions in the United States: part I," Arthritis and Rheumatism, vol. 58, no. 1, pp. 15-25, 2008.

[4] L. Murphy, T. A. Schwartz, C. G. Helmick et al., "Lifetime risk of symptomatic knee osteoarthritis," Arthritis \& Rheumatism, vol. 59, no. 9, pp. 1207-1213, 2008.

[5] P. J. Mork, A. Holtermann, and T. I. L. Nilsen, "Effect of body mass index and physical exercise on risk of knee and hip osteoarthritis: longitudinal data from the Norwegian HUNT Study," Journal of Epidemiology and Community Health, vol. 66, no. 8, pp. 678-683, 2012.

[6] F. F. Zhang, J. B. Driban, G. H. Lo et al., "Vitamin D deficiency is associated with progression of knee osteoarthritis," Journal of Nutrition, vol. 144, no. 12, pp. 2002-2008, 2014.

[7] G. Jones, H. M. Cooley, and N. Bellamy, "A cross-sectional study of the association between Heberden's nodes, radiographic osteoarthritis of the hands, grip strength, disability and pain," Osteoarthritis and Cartilage, vol. 9, no. 7, pp. 606-611, 2001.

[8] B. Lu, O. Ahmad, F.-F. Zhang et al., "Soft drink intake and progression of radiographic knee osteoarthritis: data from the osteoarthritis initiative," BMJ Open, vol. 3, no. 7, Article ID e002993, 2013.

[9] B. Lu, J. B. Driban, J. Duryea, T. McAlindon, K. L. Lapane, and C. B. Eaton, "Milk consumption and progression of medial tibiofemoral knee osteoarthritis: data from the osteoarthritis initiative," Arthritis Care and Research, vol. 66, no. 6, pp. 802809, 2014.

[10] H. M. Cooley, J. Stankovich, and G. Jones, "The association between hormonal and reproductive factors and hand osteoarthritis," Maturitas, vol. 45, no. 4, pp. 257-265, 2003.

[11] V. K. Srikanth, J. L. Fryer, G. Zhai, T. M. Winzenberg, D. Hosmer, and G. Jones, "A meta-analysis of sex differences prevalence, incidence and severity of osteoarthritis," Osteoarthritis and Cartilage, vol. 13, no. 9, pp. 769-781, 2005.

[12] F. Rees, S. Doherty, M. Hui et al., "Distribution of finger nodes and their association with underlying radiographic features of osteoarthritis," Arthritis Care and Research, vol. 64, no. 4, pp. 533-538, 2012.
[13] A. N. Bastick, J. N. Belo, J. Runhaar, and S. M. A. BiermaZeinstra, "What are the prognostic factors for radiographic progression of knee osteoarthritis? A meta-analysis," Clinical Orthopaedics and Related Research, vol. 473, no. 9, pp. 29692989, 2015.

[14] C. Ding, F. Cicuttini, L. Blizzard, and G. Jones, "Smoking interacts with family history with regard to change in knee cartilage volume and cartilage defect development," Arthritis and Rheumatism, vol. 56, no. 5, pp. 1521-1528, 2007.

[15] D. T. Felson, J. J. Anderson, A. Naimark, M. T. Hannan, W. B. Kannel, and R. F. Meenan, "Does smoking protect against osteoarthritis?” Arthritis \& Rheumatism, vol. 32, no. 2, pp. 166$172,1989$.

[16] Y. Zhang, C. Zeng, H. Li et al., "Relationship between cigarette smoking and radiographic knee osteoarthritis in Chinese population: a cross-sectional study," Rheumatology International, vol. 35, no. 7, pp. 1211-1217, 2015.

[17] E. J. Timmermans, L. A. Schaap, F. Herbolsheimer et al., "The influence of weather conditions on joint pain in older people with osteoarthritis: results from the European Project on OSteoArthritis," The Journal of Rheumatology, vol. 42, no. 10, pp. 1885-1892, 2015.

[18] M. Kloppenburg, "Hand osteoarthritis—an increasing need for treatment and rehabilitation," Current Opinion in Rheumatology, vol. 19, no. 2, pp. 179-183, 2007.

[19] Y. Zhang, J. Niu, M. Kelly-Hayes, C. E. Chaisson, P. Aliabadi, and D. T. Felson, "Prevalence of symptomatic hand osteoarthritis and its impact on functional status among the elderly: the framingham study," American Journal of Epidemiology, vol. 156, no. 11, pp. 1021-1027, 2002.

[20] S. A. Oliveria, D. T. Felson, J. I. Reed, P. A. Cirillo, and A. M. Walker, "Incidence of symptomatic hand, hip, and knee osteoarthritis among patients in a health maintenance organization," Arthritis \& Rheumatism, vol. 38, no. 8, pp. 11341141, 1995.

[21] R. Altman, G. Alarcón, D. Appelrouth et al., "The American College of Rheumatology criteria for the classification and reporting of osteoarthritis of the hand," Arthritis and Rheumatism, vol. 33, no. 11, pp. 1601-1610, 1990.

[22] U. Irlenbusch and G. Dominick, "Investigations in generalized osteoarthritis. Part 2," Osteoarthritis and Cartilage, vol. 14, pp. 428-434, 2006.

[23] K. Klein and S. Gay, "Epigenetics in rheumatoid arthritis," Current Opinion in Rheumatology, vol. 27, no. 1, pp. 76-82, 2015.

[24] U.S. Department of Health and Human Services, The Health Consequences of Smoking-50 Years of Progress. A Report of the Surgeon General, U.S. Department of Health and Human Services, Centers for Disease Control and Prevention, National Center for Chronic Disease Prevention and Health Promotion, Office on Smoking and Health, Atlanta, Ga, USA, 2014, http:// www.cdc.gov/tobacco/data_statistics/sgr/50th-anniversary/ index.htm.

[25] OAI, Study Overview and Objectives, 2013, https://oai.epi-ucsf .org/datarelease/StudyOverview.asp.

[26] M. M. Haara, M. H. Kröger, J. P. A. Arokoski et al., "Osteoarthritis of finger joints in Finns aged 30 or over: prevalence, determinants, and association with mortality," Annals of the Rheumatic Diseases, vol. 62, no. 2, pp. 151-158, 2003.

[27] L. Kalichman and E. Kobyliansky, "Hand osteoarthritis in Chuvashian population: prevalence and determinants," Rheumatology International, vol. 30, no. 1, pp. 85-92, 2009. 
[28] F. V. Wilder, B. J. Hall, and J. P. Barrett, "Smoking and osteoarthritis: is there an association? The Clearwater Osteoarthritis study," Osteoarthritis and Cartilage, vol. 11, no. 1, pp. 29-35, 2003.

[29] D. J. Hart and T. D. Spector, "Cigarette smoking and risk of osteoarthritis in women in the general population: the Chingford study," Annals of the Rheumatic Diseases, vol. 52, no. 2, pp. 93-96, 1993.

[30] A. Samanta, A. Jones, M. Regan, T. S. Wilson, and M. Doherty, "Is osteoarthritis in women affected by hormonal changes or smoking?" British Journal of Rheumatology, vol. 32, no. 5, pp. 366-370, 1993.

[31] L. Gullahorn, L. Lippiello, and R. Karpman, "Smoking and osteoarthritis: differential effect of nicotine on human chondrocyte glycosaminoglycan and collagen synthesis," Osteoarthritis and Cartilage, vol. 13, no. 10, pp. 942-943, 2005.

[32] X. Ying, S. Cheng, Y. Shen et al., "Nicotine promotes proliferation and collagen synthesis of chondrocytes isolated from normal human and osteoarthritis patients," Molecular and Cellular Biochemistry, vol. 359, no. 1-2, pp. 263-269, 2012.

[33] Y. Uematsu, H. Matuzaki, and M. Iwahashi, "Effects of nicotine on the intervertebral disc: an experimental study in rabbits," Journal of Orthopaedic Science, vol. 6, no. 2, pp. 177-182, 2001.

[34] A. Jamal, I. T. Agaku, E. O’Connor, B. A. King, J. B. Kenemer, and L. Neff, "Current cigarette smoking among adults-united States, 2005-2013," Morbidity and Mortality Weekly Report, vol. 63, no. 47, pp. 1108-1112, 2014. 


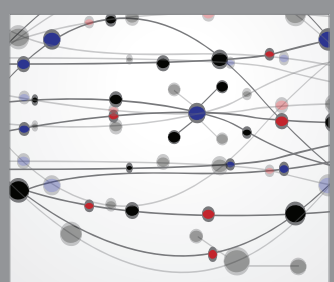

The Scientific World Journal
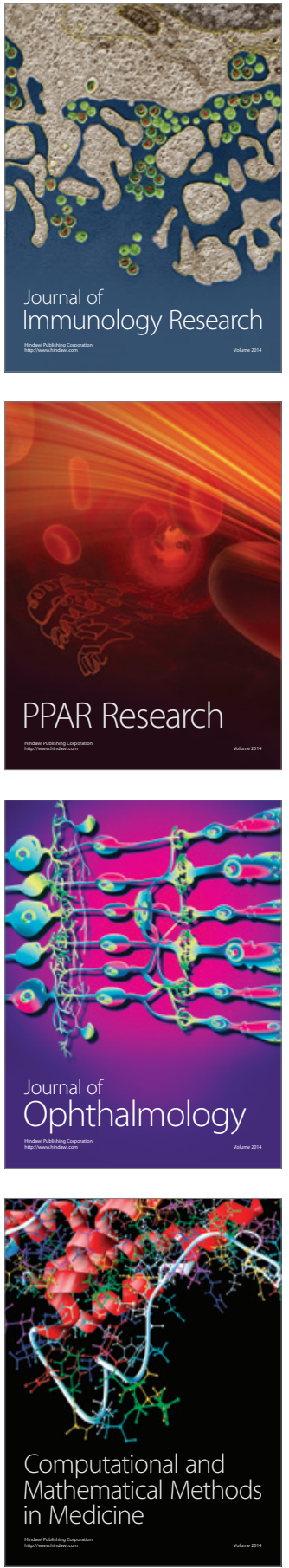

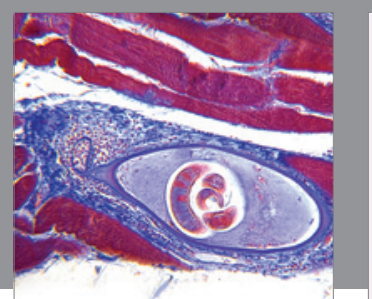

Gastroenterology Research and Practice

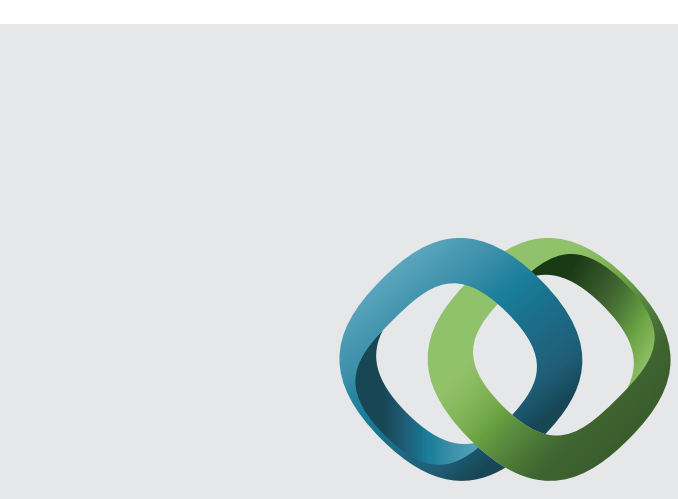

\section{Hindawi}

Submit your manuscripts at

http://www.hindawi.com
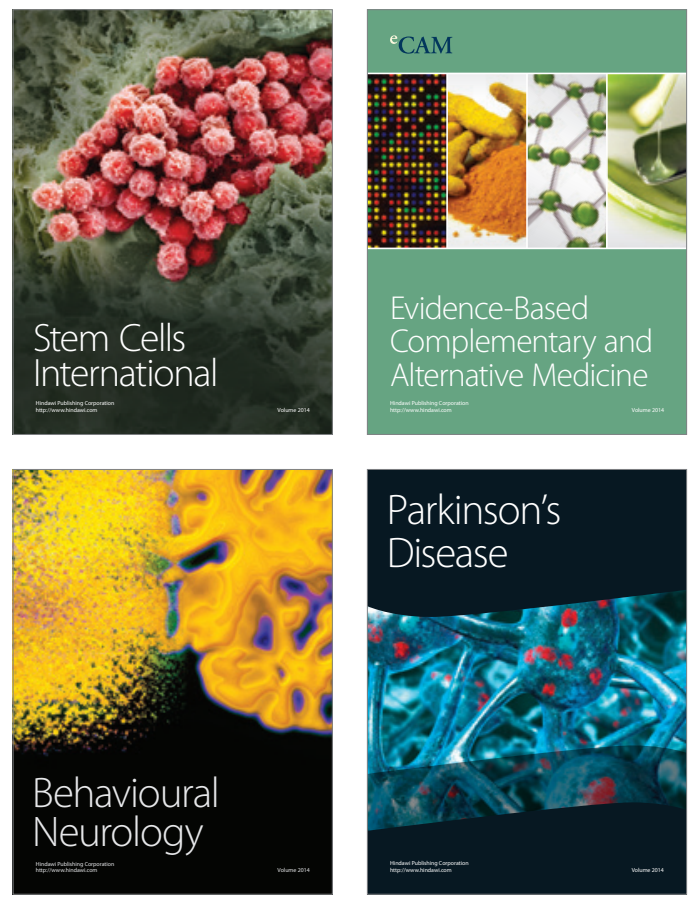
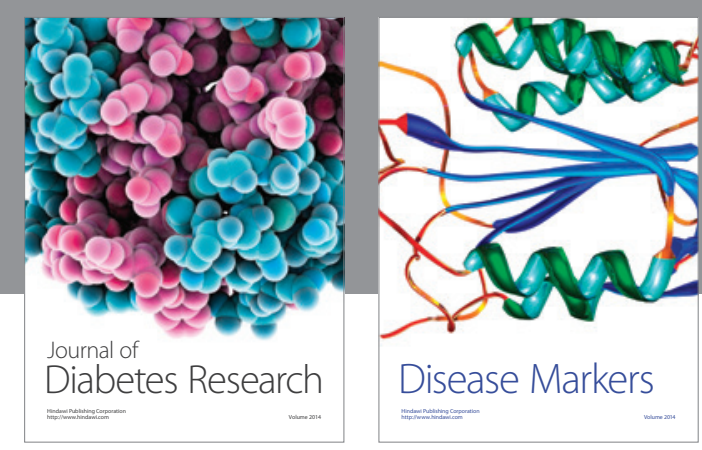

Disease Markers
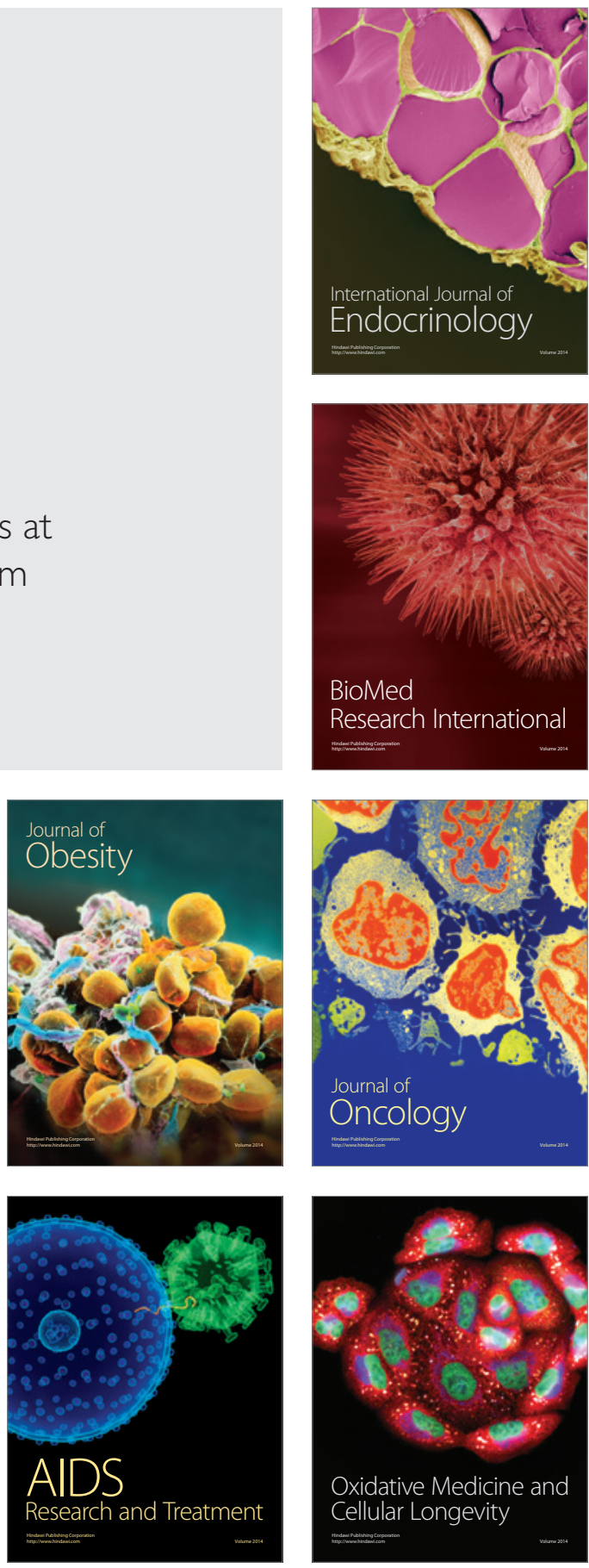